mgr inz. Tomasz Antkowiak

mgr inz. Radostaw Miklasz

Instytut Pojazdów Szynowych , TABOR”

\title{
Modernizacja wózka 1 LNb przeznaczonego dla lokomotywy 6Dk
}

\begin{abstract}
$W$ artykule przedstawiono modernizacje wózka $1 L N b$ (powstałego na bazie wózka $1 L N)$ przeznaczonego dla lokomotywy manewrowej 6Dk. Scharakteryzowano zmodernizowane węzły konstrukcyjne wózka. Porównano wózek $1 \mathrm{LNb} z$ wózkiem $1 L N$ w zakresie części poddanych modernizacji
\end{abstract}

\section{Wstęp}

Duża ilość obecnie eksploatowanych pojazdów na terenie Polski jest już przestarzała $z$ technicznego punktu widzenia. Powodem takiego stanu jest fakt, iż produkowane były przez wiele lat bez wprowadzania zasadniczych zmian konstrukcyjnych. Pojazdy te charakteryzowały się stosunkowo dużą awaryjnością i wysokimi kosztami eksploatacyjnymi.

Doświadczenia kolei zachodnich stanowią podstawę do stwierdzenia, że tego typu pojazdy powinny być modernizowane przynajmniej dwa razy podczas okresu swojej trwałości.

Głównym zadaniem modernizacji pojazdu jest:

- zmniejszenie kosztów eksploatacji, obsługi i napraw,

- podniesienie parametrów technicznych, ekologicznych i sprawności,

- poprawa bezpieczeństwa i komfortu pracy obsługi [1].

Wśród wielu lokomotyw manewrowych, eksploatowanych w naszym kraju do modernizacji kwalifikuje się lokomotywa spalinowa SM 42 (6D).

O wyborze $\mathrm{w} / \mathrm{w}$ lokomotywy do modernizacji świadczy fakt, iż lokomotywa SM42 jest jedną $\mathrm{z}$ najliczniej eksploatowanych lokomotyw w Polsce, wykorzystywanych do prac manewrowych i przewozowych. Odbiorcami tych lokomotyw, produkowanych w latach 1965-1992, były głównie PKP oraz zakłady przemysłowe. Łącznie powstało ponad 2000 sztuk tych lokomotyw.

Najszerszą jak dotąd i najbardziej dopasowaną do wykonywanych zadań modernizację lokomotywy SM42 przeprowadzono w zakładzie PESA w Bydgoszczy przy udziale Instytutu Pojazdów Szynowych w Poznaniu.

Niniejszy artykuł ma na celu przedstawienie modernizacji układów biegowych wózków 1LN, lokomotywy 6Dk (oznaczenie po w/w modernizacji).

\section{Modernizacja wózka 1LN}

\subsection{Charakterystyka wózka $1 \mathrm{LNb}$}

Wózek $1 \mathrm{LNb}$ powstał $\mathrm{w}$ oparciu o konstrukcję wózka typu 1LN i swoje zastosowanie znalazł $\mathrm{w}$ zmodernizowanej dwuagregatowej lokomotywie 6Dk (SM42). Projekt modernizacji wózka opierał się na założeniu, że przeznaczeniem lokomotywy 6Dk jest: wykonywanie prac manewrowych na terenie bocznic kolejowych, stacji manewrowych i rozrządowych oraz prowadzenie pociagów towarowych. Modernizacja wózka 1LN miała na celu poprawę skuteczności hamowania lokomotywy oraz umożliwienie jej przejazdu przez łuk toru o minimalnym promieniu $R$ $=60 \mathrm{~m}$. Parametry te można było poprawić przez odpowiednią modyfikację układu biegowego, umożliwiającą zabudowę nowego układu hamulcowego oraz przebudowę ograniczników skrętu wózka. Konstrukcja wózka charakteryzuje się prostotą budowy i posiada szereg detali i podzespołów zunifikowanych z wózkami eksploatowanych lokomotyw SM42 [2].

$\mathrm{W}$ tabeli 1 przedstawiono charakterystykę techniczną wózka $1 \mathrm{LNb}$.

\subsection{Opis zmodernizowanych części wózka $1 \mathrm{LNb}$}

Układ konstrukcyjny wózka $1 \mathrm{LNb}$ został przedstawiony na rys. 1 . Modernizacji wózka zostały poddane następujące grupy konstrukcyjne (rys. 1):

- rama wózka - w zakresie zmiany wsporników (poz. 1),

- odgarniacz na wózku (poz. 2),

- prowadzenie boczne silnika trakcyjnego (poz. 3),

- układ hamulca na wózku - w zakresie zmiany ilości i sposobu zamocowania cylindrów hamulcowych(poz. 4),

- układ napędu nadajnika prędkościomierza (poz. 5), 
- układ nadajników prędkości do układu przeciwpoślizgowego (poz. 6),

- układ piasecznic na wózku (poz. 7),

- układ przewodów smarnych systemu REBS (smarowanie obrzeży kół na wózku - poz. 8),

- układ przewodów powietrznych na wózku (poz. 9),

- osłony przekładni na wózku (poz. 10),

- orurowanie przewodów elektrycznych na wózku (poz. 11).

Charakterystyka techniczna wózka 1LNb

Tabela 1

\begin{tabular}{|c|c|}
\hline Szerokość toru & $1435 \mathrm{~mm}$ \\
\hline $\begin{array}{l}\text { Rozstaw osi zestawów kołowych } \\
\text { (baza wózka) }\end{array}$ & $2600 \mathrm{~mm}$ \\
\hline $\begin{array}{l}\text { Średnica okręgu tocznego koła (w } \\
\text { stanie nowym) }\end{array}$ & $1100 \mathrm{~mm}$ \\
\hline Nacisk zestawu kołowego na tor & $17 \mathrm{t}$ \\
\hline Szerokość obręczy kół & $140 \mathrm{~mm}$ \\
\hline $\begin{array}{l}\text { Rozstaw środków maźnic zestawu } \\
\text { kołowego }\end{array}$ & $2060 \mathrm{~mm}$ \\
\hline $\begin{array}{l}\text { Ugięcie statyczne usprężynowania I- } \\
\text { go stopnia }\end{array}$ & $50 \mathrm{~mm}$ \\
\hline $\begin{array}{l}\text { Ugięcie statyczne usprężynowania II- } \\
\text { go stopnia }\end{array}$ & $83 \mathrm{~mm}$ \\
\hline $\begin{array}{l}\text { Przesuw poprzeczny wózka względem } \\
\text { pudła }\end{array}$ & $25 \mathrm{~mm}$ \\
\hline $\begin{array}{l}\text { Największy luz między ograniczni- } \\
\text { kami obrotu }\end{array}$ & $65 \mathrm{~mm}$ \\
\hline $\begin{array}{l}\text { Najmniejszy łuk toru, przez który } \\
\text { może przejechać lokomotywa }\end{array}$ & $60 \mathrm{~m}$ \\
\hline $\begin{array}{l}\text { Maksymalny kąt skrętu wózka } \\
\text { (między ogranicznikami) }\end{array}$ & $3^{\circ} 37^{\prime} 35^{\prime \prime}$ \\
\hline $\begin{array}{l}\text { Największy przesuw poprzeczny } \\
\text { zestawu kołowego względem ramy } \\
\text { wózka }\end{array}$ & $7 \mathrm{~mm}$ \\
\hline Hamulec - typ: & $\begin{array}{l}\text { - pneumatyczno mecha- } \\
\text { niczny } \\
\text { - pneumatyczno- } \\
\text { mechaniczny } \\
\text { - wariant z hamulcem po- } \\
\text { stojowym }\end{array}$ \\
\hline Cylinder hamulcowy: & $\begin{array}{ll} & \text { BCRK 140N } \\
\text { - } & \text { BCRK 140NPS } \\
\end{array}$ \\
\hline Klocki hamulcowe: & $\begin{array}{c}\text { pojedyncze bez obrzeża (typu } \\
\text { D0-380) }\end{array}$ \\
\hline $\begin{array}{l}\text { Ciśnienie w cylindrze hamulcowym: } \\
\text { - BCRK 140N: } \\
\text { - max ciśnienie hamulca służbo- } \\
\text { wego HS } \\
\text { - BCRK 140NPS: } \\
\text { - max ciśnienie hamulca służbo- } \\
\text { wego HS } \\
\text { - max ciśnienie hamulca posto- } \\
\text { jowego HP } \\
\text { - min ciśnienie hamulca postojo- } \\
\text { wego HP }\end{array}$ & $\begin{array}{l}5 \text { bar } \\
5 \text { bar } \\
8 \text { bar } \\
5 \text { bar }\end{array}$ \\
\hline Skrajnia wózka & wg karty UIC-505 \\
\hline
\end{tabular}

\subsubsection{Rama wózka}

Rama wózka stanowi konstrukcję spawaną, składającą się $\mathrm{z}$ dwu podłużnic połączonych $\mathrm{w}$ środku poprzecznicą.

Modernizacja ramy miała charakter dwufazowy. W pierwszej fazie sprawdzono możliwość zabudowy nowego układu hamulcowego na ramie wózka $1 \mathrm{LN}$. W drugiej fazie usunięto elementy powodujące kolizję z nowym układem hamulcowym i skonstruowano nowe wsporniki do montażu elementów układu hamulcowego.

W związku z tym, że modernizacja objęła znaczną przebudowę wsporników głównie zawieszenia hamulca, zadecydowano o tym, aby ramę poddać ponownie obliczeniom wytrzymałościowym.

Obliczenia zostały wykonane metodą MES. Model obliczeniowy ramy został przedstawiony na rys. 2 [3].

Po przeprowadzeniu obliczeń, stwierdzono że poziom naprężeń powstających w ramie wózka dla nadzwyczajnego obciążenia pionowego, bocznego, wichrowania i obciążenia pochodzącego od nadzwyczajnego hamowania oraz superpozycji nadzwyczajnego obciążenia pionowego $\mathrm{z}$ obciążeniem pochodzącym od hamulca nie przekracza wartości dopuszczalnych przyjętych wg norm [3].

Dodatkowo zalecono wykonawcy przeprowadzenie odprężania wibracyjnego w celu znacznej redukcji naprężeń spawalniczych.

Dzięki temu zabiegowi możliwe jest uzyskanie:

- stabilizacji wymiarowej ramy, korzystnej $\mathrm{w}$ aspekcie prawidłowego funkcjonowania wózka podczas eksploatacji,

- podwyższenia trwałości eksploatacyjnej ramy [4].

\subsubsection{Piasecznice i odgarniacz na wóz-} $\mathrm{ku}$

Pionowe umieszczenie cylindrów (rys. 3) w rejonach przedniej części ramy wymusiło między innymi zmianę konstrukcyjną odgarniacza oraz potrzebę zastosowania elastycznego przewodu łączącego zbiornik piasku z dyszą rozprowadzającą. Przy modernizacji tych elementów należało przewidzieć możliwość regulacji położenia odgarniacza 

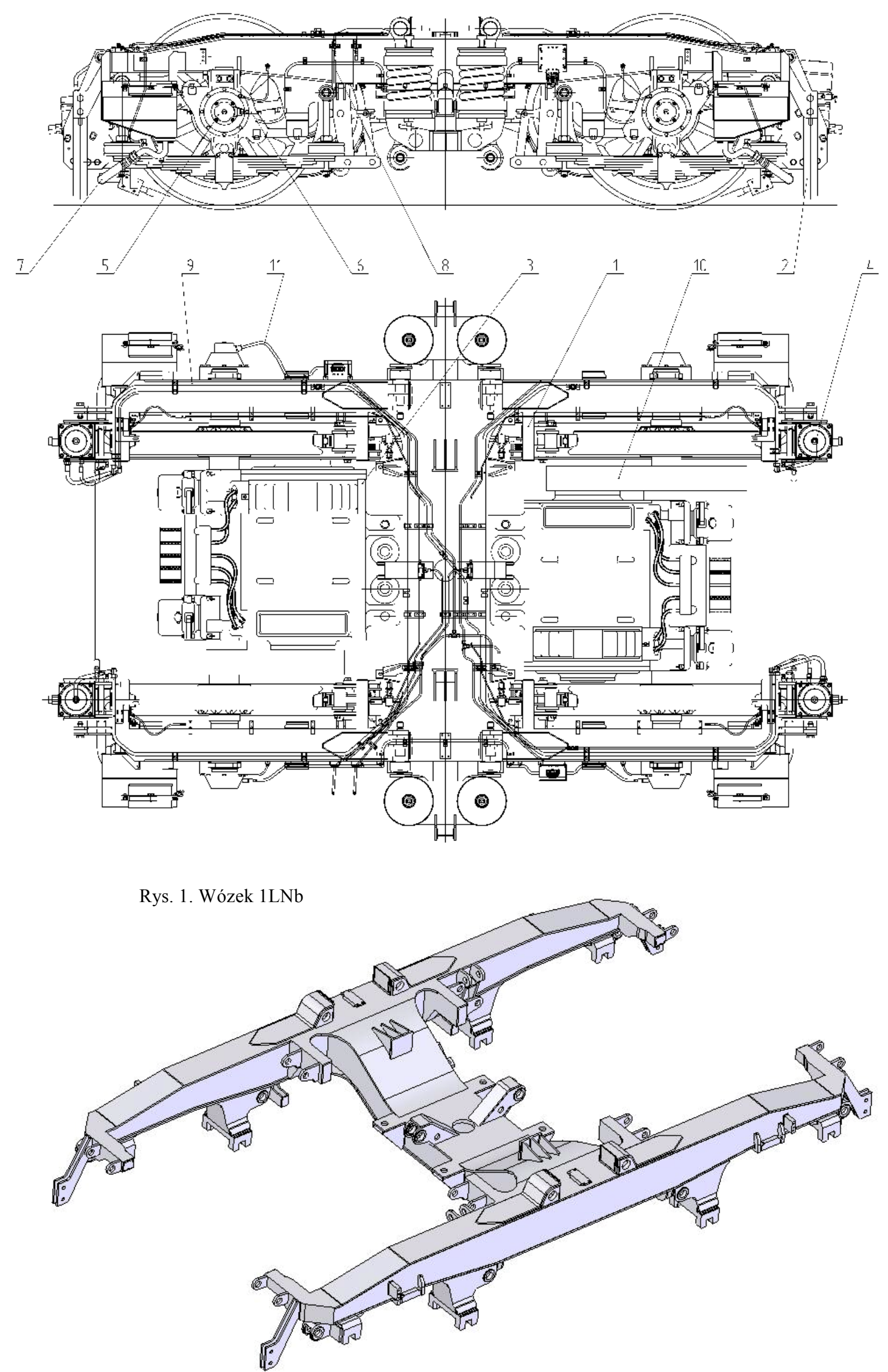

Rys. 2. Model obliczeniowy ramy wózka 1LNb [3] 


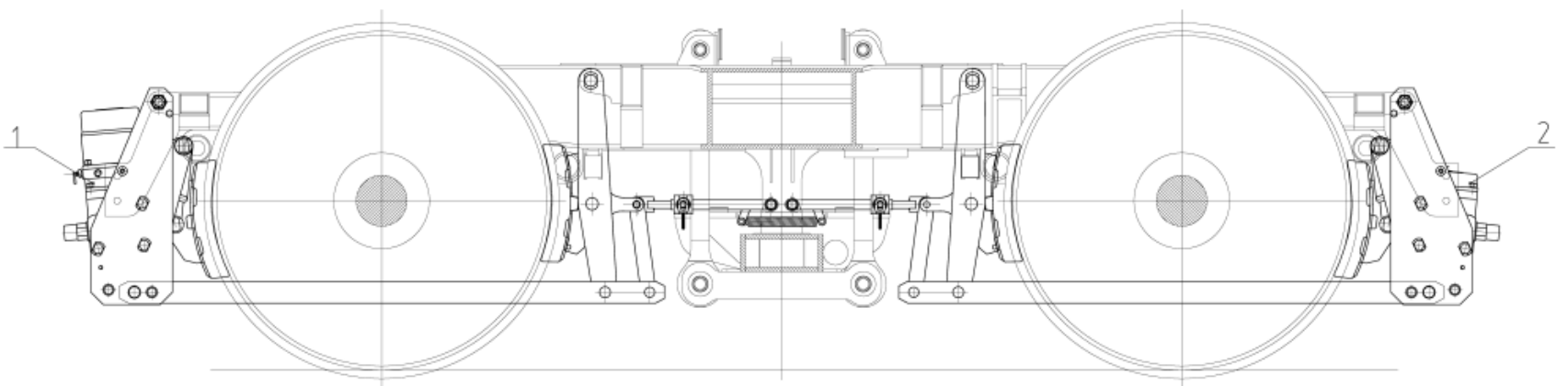

Rys. 3. Układ hamulca na wózku 1LNb

(związanej ze zmniejszaniem się średnicy tocznej kół) oraz dyszy rozprowadzającej w stosunku do główki szyny.

\subsubsection{Prowadzenie boczne silnika trakcyjnego}

Modernizacja tego węzła polegała na nieznacznej zmianie konstrukcji sworznia łączącego prowadniki silnika z ramą wózka.

2.2.4. Układ nadajników prędkości do układu przeciwpoślizgowego

W związku z wprowadzeniem do lokomotywy $6 \mathrm{Dk}$ układu przeciwpoślizgowego pozwalającego zwiększyć wydajność układu hamulcowego oraz zabezpieczyć powierzchnie toczne kół przed powstawaniem tzw. „płaskich miejsc" zamontowano w pokrywie maźnicy każdej osi czujniki prędkości.

\subsubsection{Układ hamulca na wózku}

Układ hamulca na wózku przedstawiony został na rys. 3 .

Wózek wyposażony jest w dwa rodzaje hamulca: hamulec pneumatyczno-mechaniczny (poz. 2) oraz hamulec pneumatyczno-mechaniczny $\mathrm{z}$ hamulcem postojowym (poz. 1).

$\mathrm{Na}$ każde koło zestawu kołowego wózka $1 \mathrm{LNb}$ działa jedno urządzenie hamulcowe uruchamiane blokiem cylindrowym $\mathrm{z}$ przełożeniem wewnętrznym i nastawiaczem skoku tłoka: urządzenia te wyposażone są w pojedyncze wstawki żeliwne.

Hamowanie kół jest typu dwustronnego a każdy cylinder napędza układ dźwigni na jedno koło. Dodatkowo bloki cylindrowe znajdujące się po jednej stronie wózka połączone są za pomocą dzielnika luzu, którego zadaniem jest zapewnienie takiej samej odległości klocków hamulcowych od powierzchni tocznej kół.

Jedno urządzenie hamulcowe zamontowane na wózku może być uruchomione również za pomocą siłowników sprężynowych hamulca postojowego.

Dźwignie hamulcowe zabezpieczone sa, przed możliwością przesuwu poprzecznego, z jednej strony cięgnem przykręcanym do przeciwległych dźwigni, z drugiej strony odbijakiem przyspawanym do ramy wózka.

\subsubsection{Układ smarowania obrzeży kół systemu REBS}

Wózki wyposażone są $\mathrm{w}$ system smarowania obrzeży kół firmy REBS. Kompletne urządzenie do spryskiwania składa się ze sterownika, zbiornika, pompy pneumatycznej, zaworu elektromagnetycznego. $\mathrm{Na}$ wózku zamontowane są turbinowe urządzenia rozpylające, przewody elastyczne oraz dysze rozpylające.

Urządzenia do smarowania obrzeży kół mają za zadanie znaczne zmniejszenie zużycia obrzeży kół powstającego w wyniku kontaktu koła z szyną.

System smarowania obrzeży kół REBS pracuje na tzw. hydraulicznych dyszach rozpyłowych wg systemu turbinowego. Cała sieć przewodów za pompą działa jak akumulator, magazynując środek smarowy. W ten sposób w systemie przewodów znajduje się ok. 10\% środka smarowego i $90 \%$ powietrza. Dzięki temu podczas łącznego czasu rozpylania wynoszącego ok. 6 sekund, możliwe jest bardzo oszczędne spryskanie obrzeża koła przy pomocy mieszaniny środka smarowego i powietrza. Przy właściwym ustawieniu dysz rozpyłowych niemożliwe jest rozbryzgiwanie środka smarowego poza obrzeże koła.

\subsubsection{Osłony przekładni na wózku}

Ze względu na występujące wycieki oleju smarującego z przekładni, została zmodyfikowana uszczelka filcowa, która znacznie poprawiła szczelność połączenia osłony przekładni z kołem zębatym i tuleją łożyska ślizgowego silnika trakcyjnego.

2.3. Wyznaczenie minimalnego promienia przejezdności

Jednym z podstawowych parametrów podawanych $\mathrm{w}$ charakterystyce lokomotywy jest minimalny przejezdny promień łuku toru po jakim lokomotywa może poruszać się podczas wykonywania prac manewrowych. Na rys. 4 przedstawiono schematycznie usytuowanie wózków $1 \mathrm{LNb}$ na łuku o promieniu $R$. 


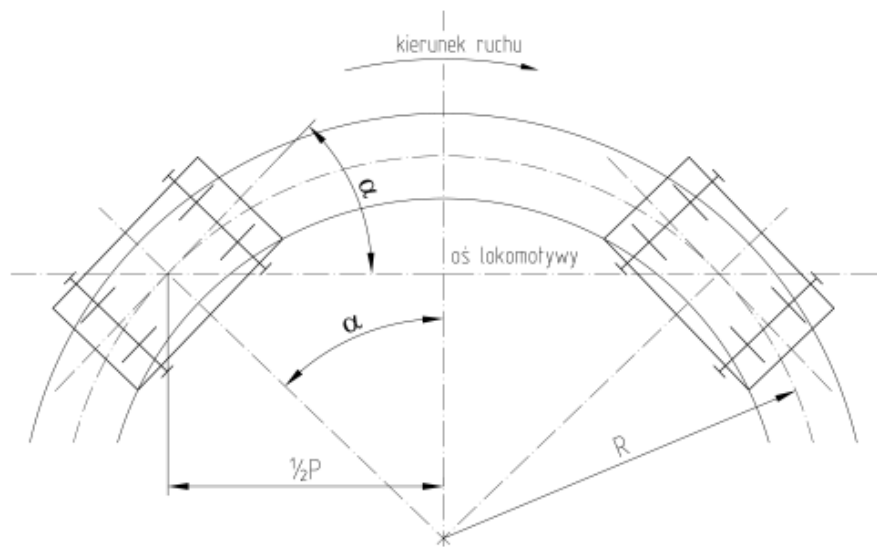

Rys. 4. Rozmieszczenie wózków lokomotywy SM42 na łuku o promieniu R [5]

Maksymalny kąt obrotu wózka względem pudła podczas przejazdu przez łuk toru o promieniu $R=60$ $\mathrm{m}$ (z tytułu geometrii toru) można wyznaczyć na podstawie wzoru

$$
\alpha=\arcsin \frac{a}{2 R}
$$

gdzie:

$a$ - baza lokomotywy,

$R$ - promień łuku.

Po wstawieniu danych liczbowych $a=7,5 \mathrm{~m}$ oraz $R=60 \mathrm{~m}$ do wzoru (1) otrzymujemy

$$
\alpha=\arcsin \frac{7,5}{120}=3,58^{\circ}
$$

Jak wcześniej wspomniano $\mathrm{w}$ celu osiągnięcia (wymaganej dla promienia łuku toru wynoszącego $R$ $=60 \mathrm{~m}$ ) wartości kąta $\alpha$ należy zmodyfikować ograniczniki skrętu wózka.

Dotychczasowe parametry konstrukcyjne lokomotywy pozwalały uzyskać kąt $\alpha=3,01^{\circ}$ tym samym umożliwiały wjazd w łuki o promieniu $R=71 \mathrm{~m}$. Kąt obrotu wózka względem pudła, jaki można uzyskać powiększając luzy na ogranicznikach do wartości $s=$ 65 mm można wyznaczyć z zależności

gdzie:

$$
\alpha=\arcsin \frac{2 s}{t}
$$

$s$ - luzy na ogranicznikach skrętu,

$t$ - odległość między odbijakami.

Po wstawieniu danych liczbowych $s=65 \mathrm{~mm}$ oraz $t=2054 \mathrm{~mm}$ do wzoru (2) otrzymujemy

$$
\alpha=\arcsin \frac{130}{2054}=3,62^{\circ}
$$

Najmniejszy promień łuku toru, po jakim swobodnie może przejechać lokomotywa można wyznaczyć ze wzoru

$$
R=\frac{a}{2 \sin \alpha}
$$

Podstawiając dane liczbowe $a=7,5 \mathrm{~m}$ oraz $\alpha=3,62^{\circ}$ otrzymujemy

$$
R=\frac{7,5}{2 \sin 3,62^{\circ}}=59,39 \mathrm{~m} \approx 60 \mathrm{~m}
$$

Ostatecznie można stwierdzić, że najmniejszy promień łuku toru, po którym przejedzie lokomotywa wyniesie $R=60 \mathrm{~m}$ tylko wówczas, gdy luz na odbijakach zostanie powiększony do wartości $s=65 \mathrm{~mm}$.

\section{Podsumowanie}

Przeprowadzona modernizacja pozwoliła na uzyskanie lepszych parametrów biegowych lokomotywy. Zmodernizowany układ hamulcowy charakteryzuje się lepszą sprawnością, mniejszą awaryjnością oraz większą skutecznością hamowania. Wymierną korzyścią przeprowadzonej modernizacji jest możliwość przejazdu przez najmniejszy promień łuku toru wynoszący $R=60 \mathrm{~m}$, ponieważ wiele zakładów obecnie użytkujących lokomotywę SM42 posiada promienie łuku toru wynoszące właśnie $60 \mathrm{~m}$.

Modernizacja wózka 1LN pozwoliła na poprawę zespołów konstrukcyjnych wózka poprzez:

- odprężanie wibracyjne zwiększające parametry wytrzymałościowe ramy,

- zastosowanie nowoczesnej pneumatyki zasilającej układ hamulcowy,

- zmianę układu mechanicznego hamulca zwiększającą skuteczność hamowania,

- modyfikację uszczelnienia zwiększająca szczelności przekładni.

Tak wykonana modernizacja wózka 1LN pozwoli na dalszą ekonomiczną i zwiększającą możliwości manewrowe oraz przewozowe eksploatację lokomotywy SM42.

\section{Li t e r a t u ra}

[1] Gardas J., Krugiotka J., Marciniak Z., Grek Z., Kozłowski W., Konstrukcja zmodernizowanej spalinowej lokomotywy manewrowej serii SM42-2000, Materiaty XII Konferencji Naukowej „Pojazdy Szynowe”, Poznań-Rydzyna 21-24 października 1996.

[2] Antkowiak T., Sobaś M., Opis techniczny wózka 1LNb, Instytut Pojazdów Szynowych TABOR, Poznań październik 2009.

[3] Kruś M., Obliczenia wytrzymałości wózka 1LNb, Instytut Pojazdów Szynowych TABOR, Poznań październik 2009.

[4] Antkowiak T., Sobaś M., Tymczasowe warunki techniczne wykonania i odbioru wózka typu 1LNb dla lokomotywy SM42 $w$ wersji dwuagregatowej, Instytut Pojazdów Szynowych TABOR, Poznań październik 2009.

[5] Grzechowiak R., Sobaś M., Analiza przejezdności modernizowanej lokomotywy SM42 (6 DK) $w$ wersji dwuagregatowej $(2 \times 400 \mathrm{~kW})$ przez tuk o minimalnym promieniu, Instytut Pojazdów Szynowych TABOR, Poznań październik 2009. 